\title{
MODIFICAÇÕES MORFOMÉTRICAS E DO CONTEÚDO PROTÉICO NA OBSTRUÇÃO EXPERIMENTAL DO CÓLON ESQUERDO
}

\author{
MORPHOMETRIC AND PROTEIN CONTENT MODIFICATIONS DURING \\ EXPERIMENTAL OBSTRUCTION OF THE LEFT COLON
}

\author{
José Eduardo de Aguilar-Nascimento, TCBC ${ }^{1}$ \\ Alberto Bicudo Salomão ${ }^{2}$ \\ Erlon Klein ${ }^{2}$ \\ Paulo Roberto Vieira de Figueiredo ${ }^{2}$ \\ Maria Helena Gaiva Gomes da Silva ${ }^{3}$
}

\begin{abstract}
RESUMO: Objetivo: Pouco se conhece a respeito das alterações colônicas que ocorrem em resposta à obstrução. O objetivo deste trabalho foi investigar as modificações morfológicas e do conteúdo de colágeno e proteínas no cólon obstruído. Método: 36 ratos Wistar foram submetidos à ligadura obstrutiva do cólon esquerdo com um fio de algodão 2-0 a 2,5cm da reflexão peritoneal. Grupos de seis animais foram sacrificados logo em seguida (0h; grupo controle) ou após 6, 12, 24, 48 e 72 horas. O comprimento e o peso do cólon foram mensurados, assim como os diâmetros $1 \mathrm{~cm}$ acima e abaixo da ligadura; na flexura esplênica e ceco. Desses mesmos pontos foram obtidas biópsias para quantificação da concentração de hidroxiprolina e proteínas. Resultados: O comprimento colônico diminuiu entre a obstrução e as observações de 6, 12 e 24 horas, retornando a valores iniciais após 48 e 72 horas. No cólon proximal à ligadura ocorreu aumento de diâmetro a partir de 6 horas, $1 \mathrm{~cm}$ acima, após 12 horas na flexura esplênica e após 24 horas no ceco. O peso do cólon aumentou após 48h $(4,6 \pm 0,5 \mathrm{~g} v s 3,4 \pm 1,1 \mathrm{~g}$; $\mathrm{p}<0,05)$. Abaixo da ligadura obstrutiva não ocorreu variação no peso das biópsias, nas dosagens de hidroxiprolina e proteínas. Proximalmente, houve aumento no peso dos espécimes após 6 horas e na concentração de hidroxiprolina após 24 horas. A dosagem de proteínas diminuiu em todos os segmentos proximais. Conclusões: $\mathrm{O}$ cólon num primeiro momento se contrai para depois alongar-se, distender-se e tornar-se mais pesado. Ocorre queda na concentração normal de proteína tecidual e uma elevação transitória seguida de diminuição de colágeno na parede colônica.
\end{abstract}

Descritores: Obstrução intestinal; Colágeno; Cólon.

\section{INTRODUÇÃO}

A busca pela melhor conduta nas operações realizadas nos casos de obstrução aguda do cólon esquerdo tem sido o objetivo de muitos trabalhos. Basicamente, toda a controvérsia situa-se na escolha do tratamento cirúrgico em um único ato operatório ou a pela opção do tratamento em dois ou três tempos ${ }^{1}$. Para muitos autores, a reconstrução imediata do trânsito intestinal aumenta de modo significativo os índices de complicações ${ }^{2,3}$. Existe, nessa situação, uma dificuldade na manipulação cirúrgica do cólon obstruído e não adequadamente preparado para o ato operatório, além das más condições gerais do paciente. No pós-operatório, quando do retorno ao peristaltismo, há ainda um risco de impactação fecal na região correspondente à linha de anastomose, aumentando assim o risco de deiscências ${ }^{4}$.

No entanto, alternativas tais como o emprego da lavagem intra-operatória do cólon com o intuito de remover

1. Professor Adjunto, Doutor em Medicina do Depto. de Cirurgia da FCM/UFMT.

2. Alunos de Medicina, bolsistas do CNPq - Programa de Iniciação Científica.

3. Professor Adjunto, Doutor da Faculdade de Enfermagem e Nutrição da UFMT.

Recebido em 08/5/2000

Aceito para publicação em 12/9/2000

Trabalho realizado no Departamento de Cirurgia da Faculdade de Ciências Médicas da Universidade Federal de Mato Grosso. 
o conteúdo fecal presente no segmento colônico proximal ${ }^{57}$ ou a realização de colectomia total ou subtotal seguida de anastomose ileorretal ou ileossigmoideana ${ }^{8}$ vêm sendo utilizadas recentemente, permitindo o tratamento da obstrução em tempo único. Os resultados do uso dessas técnicas têm apresentado índices aceitáveis e por vezes até melhores do que a abordagem em estágios ${ }^{1,5-9}$.

Entretanto, pouco se sabe sobre as alterações que se processam no nível do cólon em resposta à sua obstrução. Experimentalmente, é notável o espessamento da parede colônica às custas de hipertrofia da camada muscular e edema devido ao aumento da peristalse na tentativa de vencer a resistência do ponto obstruído ${ }^{10}$. Há ainda indícios que sugerem um incremento da síntese de proteínas na parede do órgão ocluído ${ }^{11}$. Além disso, a concentração tecidual de colágeno parece estar elevada em locais próximos à zona de obstrução ${ }^{12}$. Isso pode significar que o cólon obstruído teria, por pressuposto, boa aptidão para fixar a sutura. Essa capacidade do tecido de receber e fixar o ponto tem se mostrado como o fator mais importante para se evitar a ocorrência de deiscência nos primeiros três a quatro dias após a operação ${ }^{13}$.

Porém, não está claramente definido se tais alterações também se processam em pontos da parede colônica mais distantes da zona em que se deu a obstrução. Isto é particularmente interessante, na medida em que na maioria das operações sobre o cólon esquerdo as ressecções são amplas e as anastomoses realizadas em locais distantes do sítio de obstrução. Torna-se necessário, então, estudar as alterações intramurais que podem ocorrer durante o processo obstrutivo ao longo de todo o cólon. Assim sendo, o objetivo do presente estudo foi o de investigar, em modelo experimental de obstrução do cólon esquerdo, as alterações morfológicas e bioquímicas que se processam tanto em nível do sítio obstruído, como em outros segmentos colônicos.

\section{MÉTODO}

Trinta e seis ratos Wistar machos, provenientes do Biotério Central da Universidade Federal do Mato Grosso, com peso médio de $300 \mathrm{~g}(280-330 \mathrm{~g})$, inicialmente instalados por três dias para adaptação no Laboratório de Nutrição Experimental em ciclos de claro/escuro de 12 horas e a uma temperatura ambiente de $25^{\circ} \mathrm{C}$. A seguir, submetidos à anestesia geral, consistindo de uma injeção intraperitoneal de solução contendo tiopental sódico na dose de $30 \mathrm{mg} / \mathrm{kg}$ de peso corpóreo. Todos os animais foram então submetidos à laparotomia mediana de aproximadamente $2-3 \mathrm{~cm}$, com o objetivo de se criar obstrução intestinal conforme modelo já descrito anteriormente ${ }^{14}$. Basicamente, o cólon esquerdo era identificado e através de uma brecha no mesocólon, a $2,5 \mathrm{~cm}$ acima da reflexão peritoneal, era passado um fio de algodão 2-0 sendo o mesmo ligado com o intuito de provocar uma obstrução aguda. A síntese da parede abdominal foi feita em plano único, com pontos simples de nylon 3-0, e a seguir os ratos retornaram às suas respectivas gaiolas de origem, com dieta ad libitum.

Grupos de seis animais foram logo em seguida $(0 \mathrm{~h}=$ grupo controle) ou após 6, 12, 24, 48 e 72 horas, submetidos a nova laparotomia. Nessa segunda operação localizou-se a zona de obstrução e, em seguida, com o uso de um paquímetro, mensurou-se in situ o diâmetro do cólon nos seguintes pontos: a) $1 \mathrm{~cm}$ acima e b) $1 \mathrm{~cm}$ abaixo da ligadura obstrutiva; c) na flexura esplênica, e d) no ceco na altura da válvula ileocecal. A seguir, o animal foi sacrificado com sobredose inalatória de éter etílico.

Procedeu-se então à ressecção de todo o cólon, desde a reflexão peritoneal. Seu comprimento total foi medido com uma régua verticalizada e fixa em parede, mantendo-o tracionado pela gravidade sob o peso do ceco. O peso do cólon foi registrado em balança de precisão, após a completa remoção do conteúdo fecal.

Por fim, procedeu-se à abertura longitudinal do órgão pela sua borda antimesentérica, sendo o mesmo aplainado sobre uma placa de cortiça. Biópsias de $0,6 \mathrm{~cm}$ de diâmetro contendo todas as camadas da parede colônica foram realizadas com um punch nos mesmos pontos onde anteriormente foram realizadas as mensurações. O punch foi usado para que os fragmentos biopsiados em cada segmento tivessem aproximadamente o mesmo tamanho. Os espécimes foram pesados e em seguida congelados para serem enviados para quantificação da concentração de hidroxiprolina pelo método de Bergman e Loxley ${ }^{15}$ e de proteínas, pelo método de Lowry et al. ${ }^{16}$.

Os resultados obtidos foram comparados entre os diferentes grupos pelos testes one-way-ANOVA ou KruskalWallis, na dependência de que a distribuição dos dados estivesse de forma homogênea ou não (teste de Levene). Quando houve uma diferença significante, utilizou-se o teste de Tukey para saber-se qual ou quais grupos diferiam entre si. Estabeleceu-se em 5\% ( $\mathrm{p}<0,05)$ o nível de significância estatística. Apesar do teste não paramétrico de Kruskal-Wallis (usado apenas na variável peso do cólon) não utilizar média, todos resultados foram expressos como media \pm desvio padrão.

\section{RESULTADOS}

O comprimento do cólon sofreu uma redução significante entre o momento da obstrução $(21,3 \pm 1,6 \mathrm{~cm})$ e o observado após 6 horas $(18,1 \pm 1,7 \mathrm{~cm}), 12$ horas $(18,5 \pm$ $0,7 \mathrm{~cm})$ e 24 horas $(19,7 \pm 1,7 \mathrm{~cm})$. Após 48 horas, o comprimento retornou aos valores iniciais, ficando as medidas nos grupos de $48(20,9 \pm 1,4 \mathrm{~cm})$ e 72 horas $(20,2 \pm 1,8 \mathrm{~cm})$ significantemente superiores às encontradas nos grupos de 6,12 e 24 horas.

Na Figura 1 estão apresentados, em quatro gráficos, os resultados da mensuração do diâmetro do cólon em função do tempo de obstrução, nos diferentes pontos de observação. Abaixo da ligadura obstrutiva ocor- 


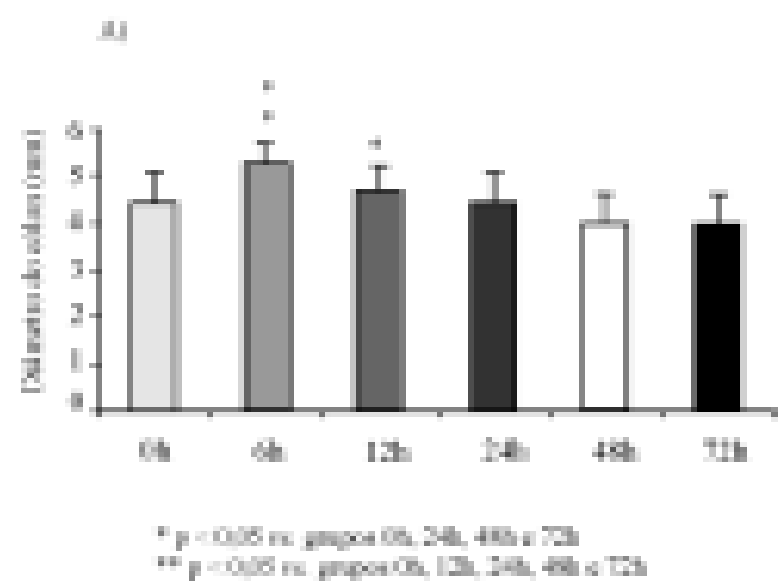

Ei

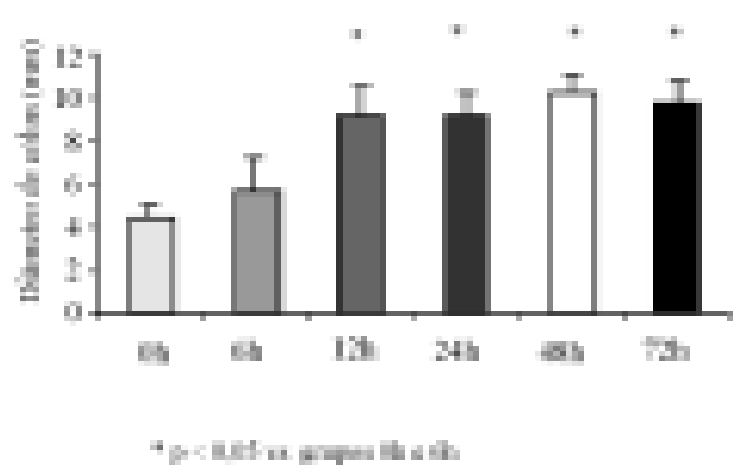

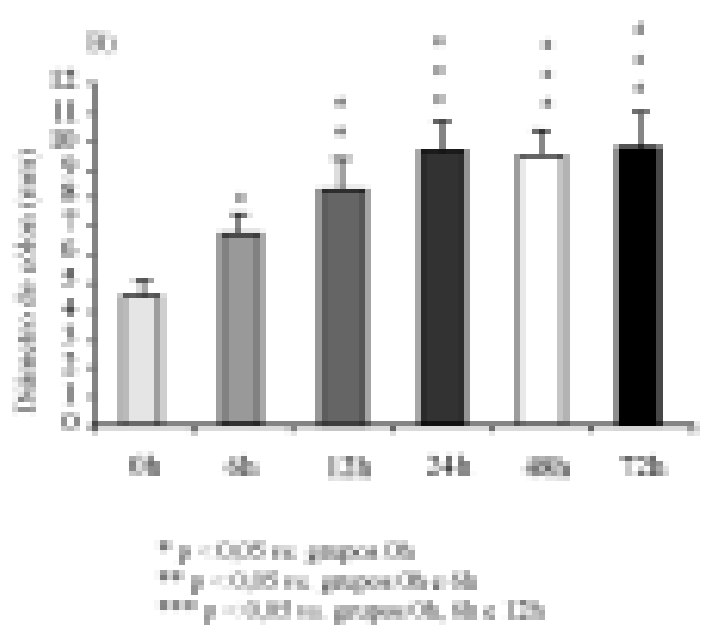

Ir

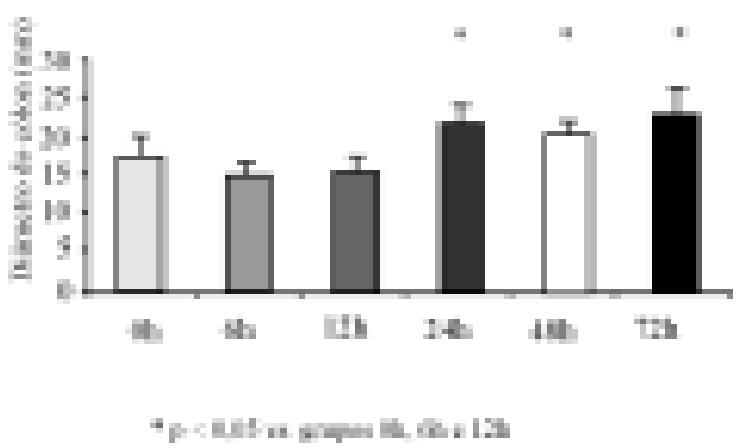

Figura 1 - Diâmetro do cólon segundo o tempo de obstrução nas regiões: a) $1 \mathrm{~cm}$ abaixo da zona de ligadura; b) $1 \mathrm{~cm}$ acima da zona de ligadura; $c$ ) flexura esplênica e d) ceco. Dados exprimem a média e o desvio-padrão.

reu um aumento significante do diâmetro colônico após 6 horas $(5,2 \pm 0,4 \mathrm{~mm})$ e 12 horas $(4,7 \pm 0,5 \mathrm{~mm})$ em relação ao observado imediatamente após a obstrução $(4,4 \pm 0,7 \mathrm{~mm})$, havendo, após esse período, regressão aos níveis normais.

No cólon proximal à ligadura, em relação ao grupo controle, ocorreu um significante aumento de diâmetro no segmento situado $1 \mathrm{~cm}$ acima da oclusão a partir de 6 horas $(6,6 \pm 0,7 \mathrm{~mm}$ vs. 4,5 $\pm 0,5 \mathrm{~mm} ; \mathrm{p}<0.05)$, na flexura esplênica a partir de 12 horas $(9,1 \pm 1,3 \mathrm{~mm} \mathrm{vs.} \mathrm{4,4 \pm 0,5}$ $\mathrm{mm} ; \mathrm{p}<0.05)$ e no ceco após 24 horas $(24,4 \pm 2,2 \mathrm{~mm} v s$. $17,4 \pm 2,5 \mathrm{~mm} ; \mathrm{p}<0.05)$. O segmento proximal, em todos os pontos estudados, atingiu o seu diâmetro máximo com 24 horas de obstrução, mantendo esses valores aproximadamente com 48 e 72 horas.

O peso do cólon sem fezes não mostrou variações estatisticamente diferentes do grupo controle $(3,4 \pm 1,1 \mathrm{~g})$ após $6(2,9 \pm 0,3 \mathrm{~g}), 12(2,9 \pm 0,2 \mathrm{~g})$ e 24 horas $(3,4 \pm$ $0,4 \mathrm{~g})$ da operação de obstrução. Entretanto, após 48 (4,6 $\pm 0,5 \mathrm{~g})$ e 72 horas $(4,5 \pm 0,6 \mathrm{~g}$.) observou-se um aumento significante de peso em relação aos valores iniciais $(\mathrm{p}<0,05)$.
Abaixo da ligadura obstrutiva não ocorreu variação no peso dos fragmentos biopsiados (Fig. 2a). No entanto, em todos os segmentos situados acima da ligadura o peso aumentou significativamente no grupo examinado com 6 horas de obstrução (Fig. 2b,c e d). Após esse aumento inicial de peso, observou-se nos demais intervalos de tempo um retorno a valores semelhantes aos encontrados no grupo controle em todos os segmentos, salvo na região correspondente à flexura esplênica onde com 72 horas de obstrução foi observado novo aumento de peso dos fragmentos que superou os valores observados após 0, 12, 24 e 48 horas.

Abaixo da ligadura obstrutiva não ocorreu variação na concentração de hidroxiprolina, conforme mostra a Figura 3a. No entanto, no segmento situado $1 \mathrm{~cm}$ acima da zona de ligadura, a concentração de hidroxiprolina aumentou significativamente nas verificações de $12(218,3 \pm 98,0 \mu \mathrm{g} /$ $100 \mathrm{~g}$ de tecido) e 24 horas $(242,8 \pm 72,1 \mu \mathrm{g} / 100 \mathrm{~g}$ de tecido) após o momento da obstrução $(135,1 \pm 26,6 \mu \mathrm{g} / 100 \mathrm{~g} \mathrm{de}$ tecido) (Fig. 3b). Da mesma forma, na flexura esplênica $(235,0 \pm 118,0 \mu \mathrm{g} / 100 \mathrm{~g}$ de tecido $v s .166,7 \pm 72,5 \mu \mathrm{g} / 100 \mathrm{~g}$ 
a)

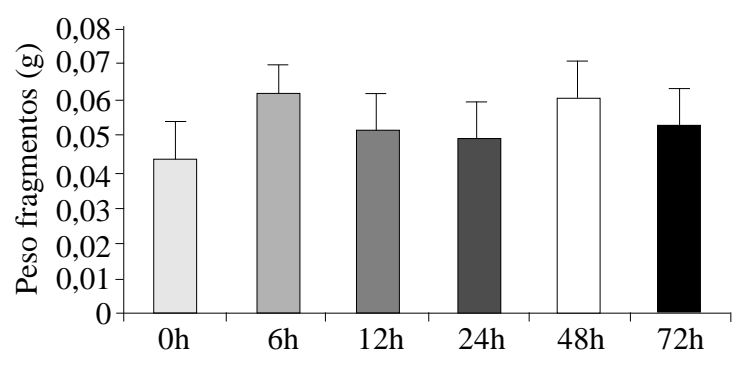

c)

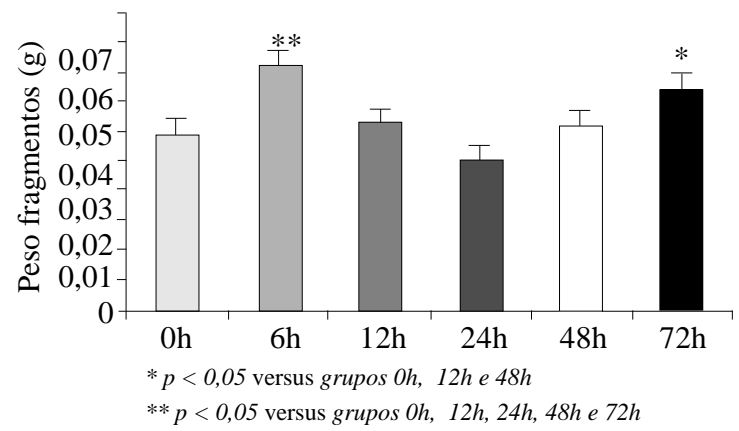

b)

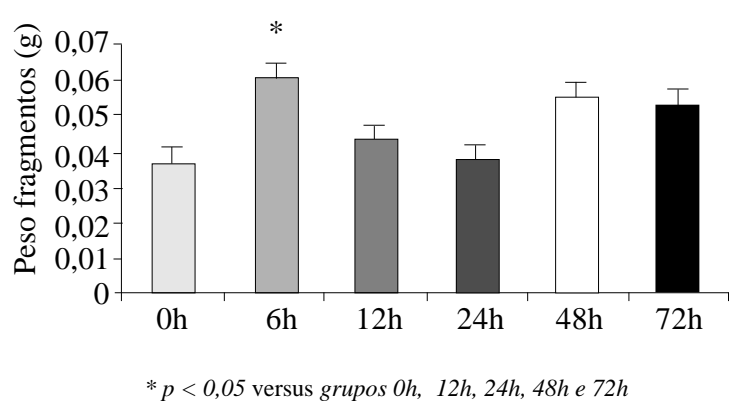

d)

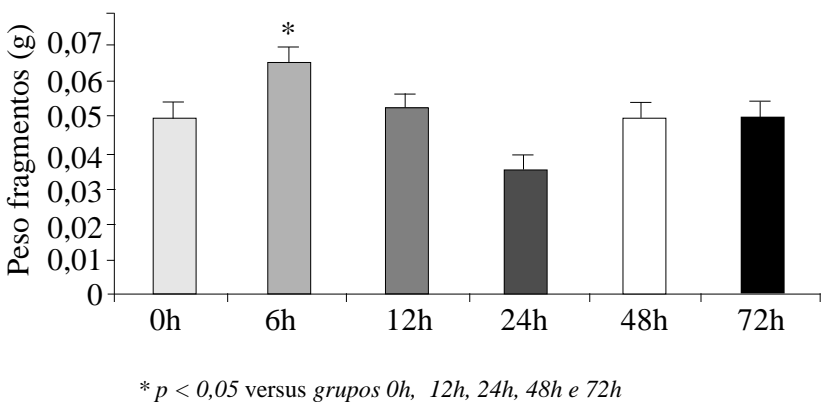

Figura 2 - Peso dos fragmentos de biópsia segundo o tempo de obstrução nas regiões: a) $1 \mathrm{~cm}$ abaixo da zona de ligadura; $\boldsymbol{b}$ ) $1 \mathrm{~cm}$ acima da zona de ligadura; c) flexura esplênica e d) ceco. Dados exprimem a média e o desvio-padrão.

de tecido; $\mathrm{p}<0.05)$ e no ceco $(263,2 \pm 55,6 \mu \mathrm{g} / 100 \mathrm{~g}$ de tecido $v s .214,7 \pm 94,2 \mu \mathrm{g} / 100 \mathrm{~g}$ de tecido; $\mathrm{p}<0.05)$, houve aumento da hidroxiprolina na observação de 24 horas em relação aos controles (Fig. 3c e 3d). Esse aumento de colágeno no cólon proximal à ligadura foi seguido em todas as regiões pesquisadas, por uma queda significante na concentração de hidroxiprolina nos achados de 48 e 72 horas em relação aos observados com 24 horas, havendo, nesses casos, um retorno a cifras similares àquelas encontradas no grupo controle.

Abaixo da ligadura obstrutiva não ocorreu variação na dosagem de proteínas (Fig. 4a). Entretanto, acima da oclusão houve uma tendência, em todas as regiões examinadas, a uma queda significante na concentração tecidual de proteínas com o passar do tempo (Fig. 4b, c e d).

\section{DISCUSSÃO}

Os resultados deste experimento demonstram que a obstrução determina profundas alterações que se processam ao longo de todo o cólon. Do ponto de vista morfoló- gico, os resultados mostram que o cólon inicialmente se contrai, havendo em um segundo momento o seu alongamento. Talvez isso decorra de um encurtamento das fibras musculares em pleno processo de contração nas fases iniciais da oclusão aguda, na tentativa de vencer o ponto obstruído. Tal processo tende a atingir um limite a partir do qual, provavelmente por um esgotamento fisiológico ou equilíbrio crônico, a víscera tende a relaxar, o que resulta no seu alongamento longitudinal. Neste modelo, esse tempo limite foi de 24 horas.

Por sua vez, no tocante ao diâmetro colônico, a dilatação no modelo estudado é crescente e não se modifica após 24 horas. Nota-se ainda, durante o evoluir da obstrução que ocorre após 48 horas, um importante aumento de peso do intestino grosso como um todo. Isso sugere a ocorrência de alterações bioquímicas na parede do cólon, seja pela existência de edema, ou pela incorporação de material sólido. Eliminando-se a água por secagem de fragmentos de biópsia, pôde-se demonstrar, em trabalho anterior, que independentemente da água, o peso se mantém elevado, reforçando a suspeita de incorporação de substâncias sólidas na parede colônica ${ }^{12}$. 


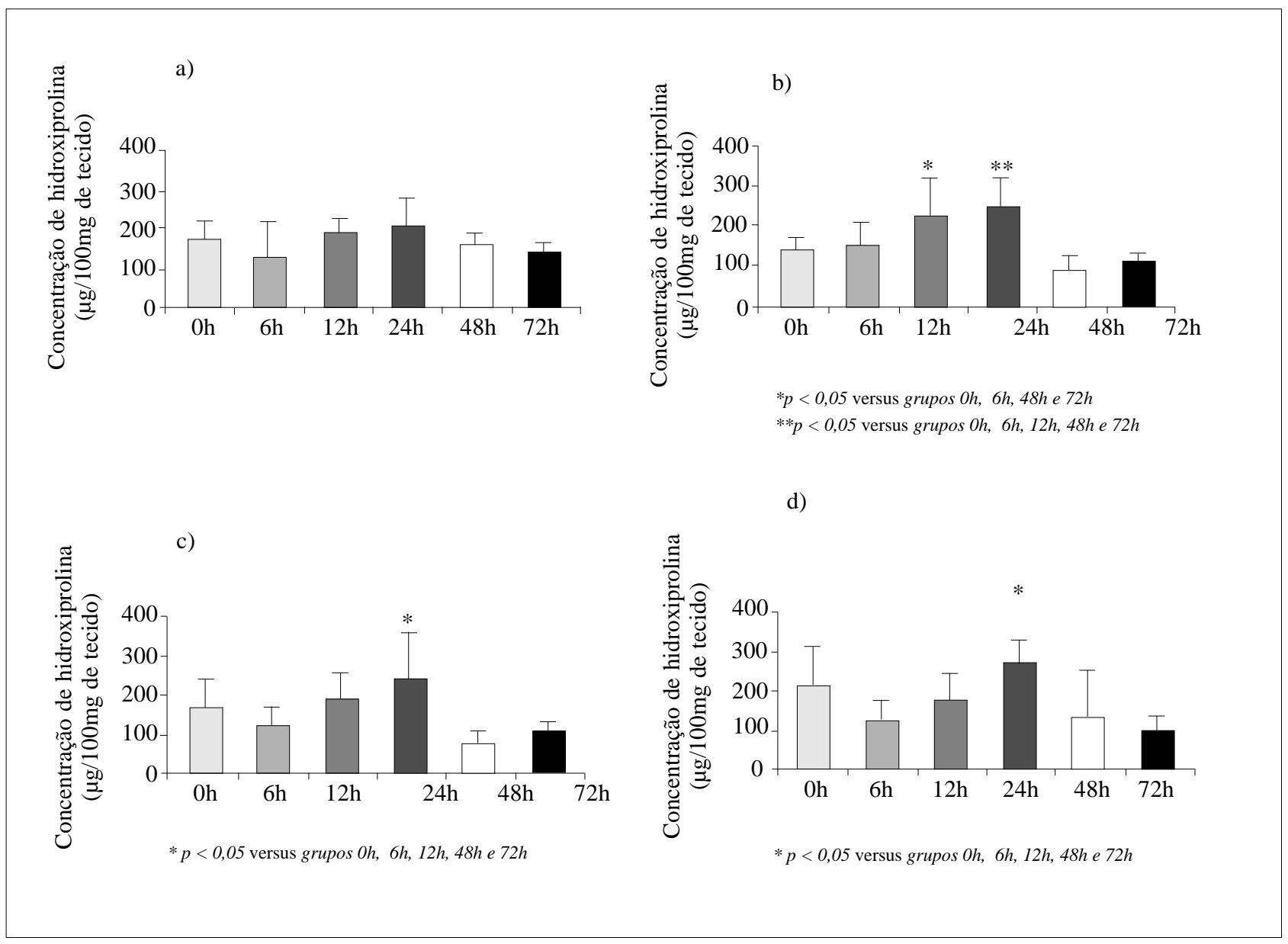

Figura 3 - Concentração de hidroxiprolina segundo o tempo de obstrução nas regiões: $\boldsymbol{a}$ ) $1 \mathrm{~cm}$ abaixo da zona de ligadura; $\boldsymbol{b}$ ) $1 \mathrm{~cm}$ acima da zona de ligadura; c) flexura esplênica e d) ceco. Dados exprimem a média e o desvio-padrão.

As dosagens bioquímicas advindas dos fragmentos de biópsia confirmaram uma intensa alteração do ponto de vista metabólico em todos os segmentos colônicos estudados neste modelo. A concentração normal de proteína tecidual mostrou queda pronunciada em todos os setores acima da ligadura. Por sua vez, com exceção da região correspondente a $1 \mathrm{~cm}$ abaixo da zona de oclusão, os níveis de hidroxiprolina tiveram uma elevação importante em todos os pontos estudados com 24 horas de obstrução. A partir daí, observou-se uma queda significativa para valores similares aos encontrados no grupo controle. Assim, conforme o que já foi observado também em outros estudos, o colágeno existente no nível da parede colônica parece ser influenciado pela oclusão aguda do cólon no sentido de haver um aumento inicial de sua síntese ${ }^{11,12}$. Da mesma forma, é importante ressaltar que tal alteração não se restringiu apenas às regiões adjacentes à zona obstruída, conforme trabalho similar já havia constatado ${ }^{9}$, mas também abrangeu outros pontos do intestino grosso mais distantes desse sítio. O método utilizado para a quantificação de proteínas e hidroxiprolina mensura a concentração desses substratos em tecido fresco ${ }^{15,16}$. Assim, devido ao edema, é possível especular que o real conteúdo de proteínas não seja tão baixo. Por outro lado, esse raciocínio também implica que o conteúdo de hidroxiprolina em 12 e 24 horas talvez seja ainda maior do que o achado.

Em estudos experimentais, tem-se admitido que a concentração elevada de colágeno no nível da parede intestinal está associada com uma melhor capacidade de cicatrização da mesma ${ }^{13,17}$. Durante os primeiros dias de pós-operatório, a resistência de uma anastomose intestinal depende quase que exclusivamente da capacidade do tecido de fixação da sutura ${ }^{18,19}$. Nessa primeira fase cuja duração, de três a quatro dias, a concentração de colágeno é baixa e assim a segurança da anastomose depende dos pon$\operatorname{tos}^{13,17-19}$. Os dados do presente estudo sugerem que, pelo menos neste modelo experimental, o tempo de 24 horas seria o período ideal para a realização da anastomose, o que teoricamente implicaria resultados satisfatórios no que diz respeito à fixação da sutura, pois o cólon teria uma concentração de colágeno elevada.

Outros estudos experimentais mostram que o cólon obstruído pode ter boa receptividade à realização de res- 


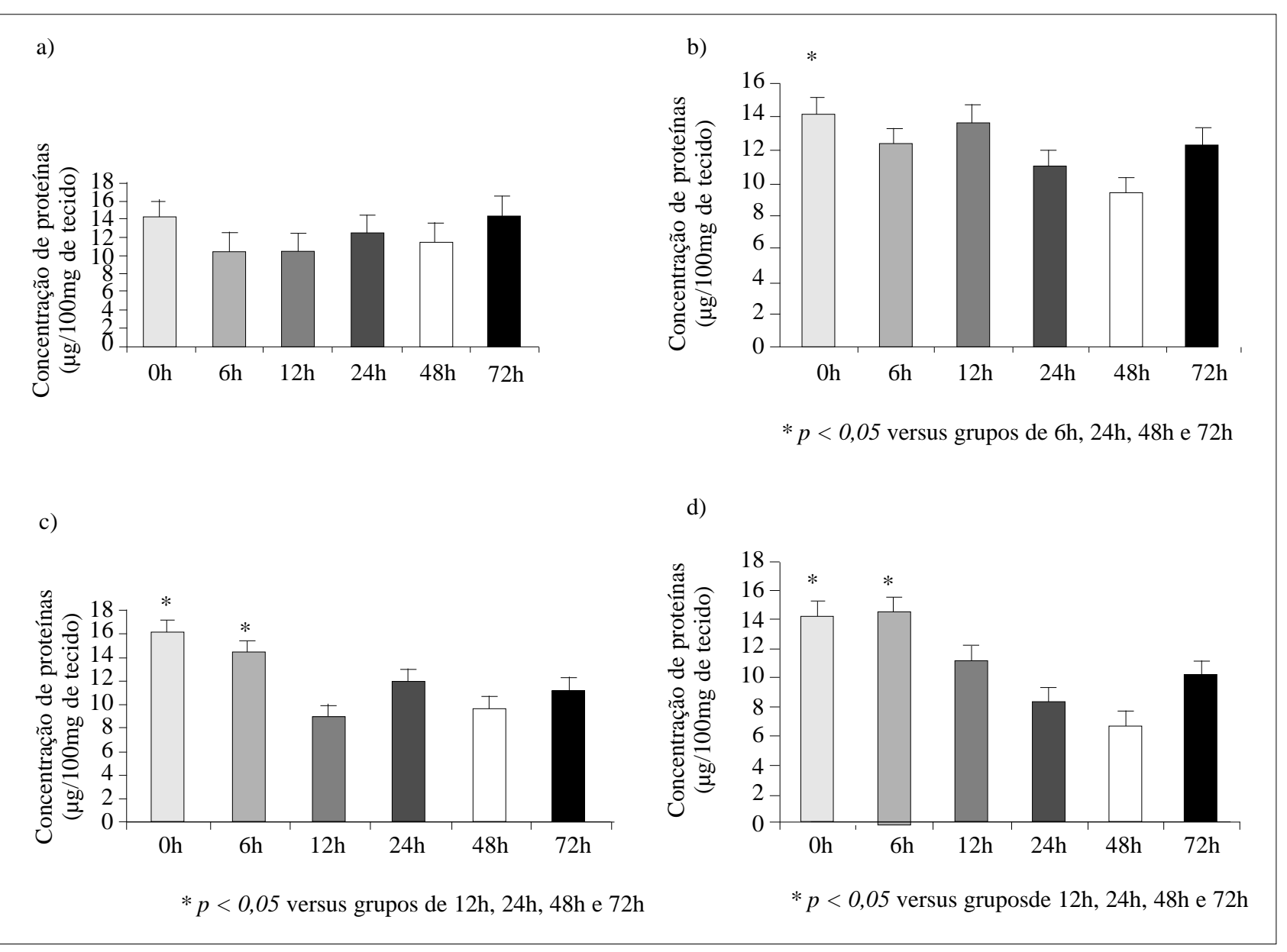

Figura 4 - Concentração de proteínas segundo o tempo de obstrução nas regiões: a) $1 \mathrm{~cm}$ abaixo da zona de ligadura; $\boldsymbol{b}$ ) $1 \mathrm{~cm}$ acima da zona de ligadura; c) flexura esplênica e d) ceco. Dados exprimem a média e o desvio-padrão.

secção e anastomose primária. Em suturas realizadas na vigência de obstrução aguda, o íleo paralítico parece ser menor do que em situação de normalidade ${ }^{20}$. Em processos de obstrução crônica sem isquemia não há alteração no sistema nervoso intrínseco do cólon ${ }^{21} \mathrm{e}$ não há diminuição do número de gânglios e neurônios na parede do órgão ${ }^{10}$. Além disso, existe um significante aumento do fluxo sangüíneo colônico na vigência de obstrução, o que pode favorecer o processo de cicatrização ${ }^{22}$. Finalmente, dados controversos sobre a resistência mecânica de anastomoses realizadas na vigência de obstrução do cólon esquerdo podem ser encontradas na literatura. Enquanto ela parece ser maior em ratos obstruídos ${ }^{11,23}$, outros trabalhos mostram que ela está mais comprometida em comparação a ratos não obstruídos ${ }^{24,25}$.

Clinicamente, entretanto, a realização de anastomose primária em cólon esquerdo obstruído é temida e muitas vezes associada a resultados insatisfatórios ${ }^{2-4}$. Esses resultados provavelmente estão associados à condição geral dos pacientes e às dificuldades de se manipular um cólon obstruído intra-operatoriamente. Isso geralmente determina um aumento da possibilidade de contaminação da cavidade peritoneal e, por conseguinte, maior risco de deiscência anastomótica ${ }^{1-9}$. A translocação bacteriana também é um importante fator a ser considerado, explicando os altos índices de complicações infecciosas associadas à obstrução ${ }^{26}$. Além disso, a impactação de fezes no pós-operatório na linha de sutura serve como um importante fator na gênese da deiscência, pois leva ao aumento exagerado da tensão sobre a anastomose, podendo propiciar a sua ruptura ${ }^{4}$.

A concentração de colágeno tecidual em todos os segmentos do cólon estudados no período de 24 horas de oclusão mostrou valores superiores aos encontrados logo após a obstrução. Isso sugere, então, que no processo obstrutivo há um período inicial favorável à aplicação de sutura, com possível melhor resposta no processo de cicatrização, de acordo com outro trabalho anterior ${ }^{12}$. Neste modelo, em torno de 24 horas seria o tempo ideal. Entretanto, extrapolações para a situação clínica devem ser feitas com extrema cautela, pois seria difícil estabelecer o período correto para o ser humano. Anastomoses construídas após esse tempo estarão sendo realizadas em um tecido com baixa concentração de colágeno e proteínas, além de estar o intestino submetido a um limite máximo de adap- 
tação às alterações morfológicas decorrentes de sua obstrução. Isso pode significar que a partir daí há comprometimento de sua integridade estrutural. Tais fatores podem explicar, em parte, os maus resultados clínicos associados à cicatrização de anastomoses do cólon esquerdo.

Pode-se afirmar, com base nesses resultados, que no processo de obstrução aguda do cólon esquerdo importantes alterações morfológicas viscerais se processam. Num primeiro momento ocorre um encurtamento e, posteriormente, o órgão torna-se mais longo, dilatado e mais pesado. O conteúdo de colágeno em todo o cólon aumenta após 24 horas de obstrução para depois retornar a valores iniciais, enquanto que a concentração de proteínas teciduais diminui progressivamente. Outros estudos são necessários para um melhor entendimento dessas transformações que ocorrem na parede do cólon durante a obstrução.

\begin{abstract}
Background: The colonic response to obstruction is poorly understood. The aim of this study was to investigate the colonic morphology and the variation of collagen and protein content during the development of a left-sided colonic obstruction. Method: 36 Wistar rats underwent a ligature obstruction of the left colon. Groups of 6 animals were killed immediately (Oh; control group) or after 6, 12, 24, 48 and 72hs after the obstruction. The length and weight of the colon were registered as well as the colonic diameter in four segments: at 1cm above and below the ligature, at the splenic flexure and at the ceccum. Biopsies of these sites, containing all layers of the colon, were assayed for hydroxyproline and protein concentration. Results: The colonic length decreased from 6 to 24 hs after obstruction, returning to normal values after 48hs. Proximally to the ligature, a significant increase of the diameter was observed at $1 \mathrm{~cm}$ above the ligature after 6hs, at the splenic flexure, after $12 \mathrm{hs}$, and at the ceccum, 24 hs later. Colonic weight was higher after $48 \mathrm{hs}(4,6 \pm 0,5 \mathrm{~g}$ vs. 3,4 $\pm 1,1 \mathrm{~g} ; \mathrm{p}<0,05)$. Below the ligature there was no variation in the weight of the specimens, neither in the hydroxyproline nor in the protein concentrations. Above the ligature however, the specimens became significantly heavier after 6hs and higher in hydroxyproline centent after 24hs. Protein content diminished in all proximal sites. Conclusions: The obstructed colon initially contracts and then progressively enlarges, dilates, and becomes heavier. After obstruction, colonic protein concentration progressively diminishes, although the hydroxyproline content transitorily increases.
\end{abstract}

Key Words: Intestinal obstruction; Collagen; Colon.

\section{REFERÊNCIAS}

1. Mackenzie S, Thompson SR, Baker LW. Management options in malignant obstrution of the left colon. Surg Gynecol Obstet, 1992; 174: 337-345.

2. Wiederkehr JS, Brenner S, Campos AC et al. Tratamento cirúrgico da oclusão intestinal por câncer de cólon e reto. Rev Bras Colo Proct, 1987; 7:135-8.

3. Monteiro MS, Barone B, Matos D. Resultados imediatos da operação de ressecção em 3 tempos em doentes com neoplasia obstrutiva de colon esquerdo e reto. Rev Bras Colo Proct, 1990; 10:9-12.

4. Irvin TT, Goligher JC. Aetiology of disruption of intestinal anastomoses. Br J Surg, 1973; 60:457-60.

5. Dudley HAF, Radcliffe AG, McGeehan D. Intraoperative irrigation of the colon to permit primary anastomosis. $\mathrm{Br}$ J Surg, 1980; 67:80-81.

6. Silva JH, Kerzner A, Donoso AC et al. Lavagem intestinal anterógrada transoperatória na obstrução do cólon esquerdo. Rev Col Bras Cir, 1991; 18:51-4.

7. Aguilar-Nascimento JE, Caporossi C, Marra JG et al. Ressecção e anastomose primária na obstrução neoplásica do cólon esquerdo com auxílio do preparo intestinal peroperatório. Rev Bras Colo Proct, 1992; 12:17-20.
8. White CM, Macfie J. Immediate colectomy and primary anastomosis for acute obstruction due to carcinoma of the left colon and rectum. Dis Colon Rectum, 1985; 28:155-7.

9. Phillips RKS, Hittinger R, Fry JS et al. Malignant large bowel obstruction. Br J Surg, 1985; 72:296-302.

10. Barbosa AJ, Tafuri WL. Ganglion cell number in hypertrophic colon above experimental stenosis. Braz J Med Biol Res, $1983 ; 16: 165-9$.

11. Tornqvist A, Blomquist $\mathrm{P}$, Ahonen $\mathrm{J}$ et al. The effect of stenosis on collagen metabolism in the colonic wall. Studies in the rat. Acta Chir Scand, 1988; 154: 389-393.

12. Aguilar-Nascimento JE, Mathie RT, Man WK et al. Collagen variation during experimental acute obstruction of the left colon. Dig Surg, 1998; 15:252-5.

13. Koruda NM, Rolandelli RH. Experimental studies on the healing of colonic anastomoses. J Surg Res, 1990; 48:504-15.

14. Aguilar-Nascimento JE, Caporossi C, Figueiredo PC et al. The influence of peroperative irrigation of the obstructed left colon in the healing of primary anastomosis: an experimental study in rats. ABCD Arq Bras Cir Dig, 1990; 5:57-62.

15. Bergman I, Loxley R. The determination of hydroxyproline in urine hydrolysates. Clin Chim Acta, 1970; 27:347-9. 
16. Lowry OH, Rosebrough NJ, Farr AL et al. Protein measurement with the folin phenol reagent. J Biol Chem, $1951 ; 193: 265-75$.

17. Hendriks T, Mastboom WJB. Healing of experimental intestinal anastomosis. Parameters for repairs. Dis Colon Rectum, 1990; 33:891-901.

18. Hermann JB, Woodward SC, Pulaski EJ. Healing of colonic anastomoses in the rat. Surg Obstet Gynecol, 1964; 119:169-75.

19. Jiborn H, Ahonen J, Zederfeldt B. Healing of experimental anastomoses: collagen metabolism in the colon after left colon resection. Am J Surg, 1980; 139:398-405.

20. Fraser ID, Condon RE, Schulte WJ et al. Bowel motility after primary ressection for colonic obstruction. Br J Surg, $1981 ; 68: 113-116$

21. Moore SW, Laing D, Melis J et al. Secondary effects of prolonged intestinal obstruction on the enteric nervous system in the rat. J Pediatr Surg, 1993; 28:1196-9.

22. Papanicolaou G, Ahn Yk, Nikas DJ. Effect of large-bowel obstruction on colonic blood flow. An experimental study. Dis Colon Rectum, 1989; 32:673-9.
23. Foster ME, Johnson CD, Billings PJ et al. Intraoperative antegrade lavage and anastomotic healing in acute colonic obstruction. Dis Colon Rectum, 1986; 29:255-9.

24. Aguilar-Nascimento JE, Caporossi C, Figueiredo PC et al. Anastomose primária em plano único na obstrução aguda do cólon esquerdo. Estudo em ratos. Rev Bras Colo-Proct, 1990; 10:143-7.

25. Aguilar-Nascimento JE, Mathie RT, Man WK et al. Enhanced intra-anastomotic healing by operative lavage with nutrient solutions in experimental left-sided colonic obstruction. Br J Surg, 1995; 82:461-4.

26. Deitch EA. Simple intestinal obstruction causes bacterial translocation in man. Arch Surg, 1989; 124:699-701

Endereço para correspondência:

Prof. Dr. José Eduardo de Aguilar-Nascimento

Rua Estevão de Mendonça 81/801

78045-200 - Cuiabá-MT

Tel.: 065-6237183 - Fax: 065 - 6247149

E-mail: aguilar@zaz.com.br 